\title{
Tres escenas inéditas de cacería en petroglifos predinásticos de Wadi Abu Subeira (Desierto Oriental, Egipto)
}

Sebastián Francisco Maydana
Universidad de Buenos Aires, Argentina

En Argentina podemos hablar de mucho más que de orillas y estancias. La Revista del Instituto de Historia Antigua Oriental es un prodigioso ejemplo de esto. El pensamiento de la periferia está vivo y en actividad, e incluso podemos presentar material inédito. Por ello, en esta oportunidad quisiera presentar una serie de imágenes inéditas de cacería de animales salvajes en el Desierto Oriental de Egipto. Los petroglifos que acompañan esta comunicación y las correspondientes infografías fueron generosamente cedidos para su primera publicación por la Dra. Gwenola Graff, del Institut de Recherche pour le Développement (IRD) de Francia y directora de la misión francesa a Wadi Abu Subeira, en el sur de Egipto. He tenido la oportunidad de trabajar junto a la Dra. Graff y su esposo, el arqueólogo Dr. Maxence Bailly, gracias a una beca de movilidad otorgada por la Facultad de Filosofía y Letras de la Universidad de Buenos Aires y que me permitió disfrutar de una fructífera estancia en la Universidad de Aix-Marseille en Aix-en-Provence el año pasado. Vaya entonces mi enorme agradecimiento y admiración por la generosidad y confianza depositada en mí, tanto por la Dra. Graff como por mi alma mater, junto con mi compromiso asumido de tratar estos descubrimientos con la debida responsabilidad.

La importancia de los petroglifos que presento en esta oportunidad es enorme, no sólo debido al obvio valor iconográfico sino también por los datos extraicónicos, inseparables de la iconografía al ser el arte rupestre una instalación. En ese sentido, la labor de la misión francesa en Wadi Abu Subeira es remarcable en varios sentidos, pero sobre todo en la exhaustividad con la que realizan la recolección de datos, fundamental para poder aprovecharlos. Como señala David Wengrow, al ser una de las características más significativas del arte rupestre su inmovilidad, si el único dato necesario para datarlo lo diera la imagen misma, esto quiere decir que para estudiarlas alcanzaría con dibujarlas y registrar su ubicación original. Este tipo de testimonios amenaza "con crear un clima de indiferencia (e incluso de estímulo) respecto a la actual destrucción del arte rupestre egipcio propiciado por la excavación de canteras y la construcción de carreteras en curso" (Wengrow, 2006: 141). La destrucción de petroglifos ha sido reportada desde las primeras exploraciones al desierto (Schweinfurth, 1912). En tiempos recientes 
Dirk Huyge (1998: 3) ha llamado la atención acerca de la extrema vulnerabilidad de los petroglifos, expuestos a los elementos y a la manipulación humana, tanto accidental o eventual como sistemática y organizada. Al retornar en 1982 a un sitio descubierto tan sólo dos años antes, Huyge se encontró con la completa destrucción de una interesante escena compuesta de tres siluetas de toros (Huyge, 1998: 9). Riemer (2009: 33) por su parte señala que, si bien el vandalismo y la destrucción criminal existen, lo más peligroso es la destrucción involuntaria, permitida por la creciente e irresponsable afluencia turística y la desprotección de los sitios (cf. Hendrickx y Gatto, 2009). En definitiva, lo interesante es que, como señalaba Wengrow, incluso la supuesta "conservación" de los petroglifos es perjudicial para su estudio. Contra esto, el Wadi Abu Subeira Rock Art Project se afana por producir la mayor cantidad de datos posible, de forma de permitir su estudio incluso por personas que no pisaron el sitio.

Wadi Abu Subeira es el nombre dado al lecho de un río paleolítico (hoy seco) subsidiario del Nilo y que nace $12 \mathrm{~km}$ al norte de Asuán, en el sur de Egipto, en la margen oriental del Nilo. El Wadi corre perpendicular al río, hacia el este, por $55 \mathrm{~km}$, y luego por medio de una red de cursos de agua secos comunica con el Mar Rojo. Conocido desde hace muchos años, se trata de un importante sitio que contiene arte rupestre (no hay a la fecha evidencia de asentamientos). En la actualidad, el sitio está dividido en dos concesiones, una otorgada al Aswan-Kom Ombo Archaeological Project, bajo la dirección de María Carmela Gatto; y la estudiada por la misión francoegipcia, que a su vez se divide en dos: al oeste, el equipo comandado por Adel Kelany, y al este por Gwenola Graff. Al momento, con tan sólo el 20\% del sitio debidamente prospectado (pero avanzando rápidamente), se ha hallado arte rupestre datado desde el Epipaleolítico a la dominación islámica (Piquette, Graff y Bailly, 2017: 884), distribuido en 137 locaciones y otros 46 yacimientos superficiales que contienen sobre todo puntas de proyectil.

Los petroglifos en cuestión están datados en la época conocida como Nagada (ca. 3900-3000 a.C.). El arte rupestre de este período contiene importante información para el estudio de las condiciones sociopolíticas de las sociedades que poblaban el Valle del Nilo y los desiertos circundantes, y plantea interrogantes en la misma medida. Son varios los "motivos" iconográficos que se pueden identificar (Judd, 2009), pero dos destacan por su persistencia y aparente exoticidad: las escenas de cacería de animales salvajes y las llamadas "procesiones de botes" (Lankester, 2013). Son exóticos, en apariencia, porque los botes solamente podían circular por el Nilo, muy lejos de donde se los figuraba; y como indica la arqueología los grupos humanos que vivían en el lugar no cazaban, sino que eran pastores y agricultores. Sin embargo, no se ven imágenes de pastoreo y agricultura, lo cual indica que éstas eran hechas con un fin distinto de la mera reproducción del mundo que veían. Pero, ¿qué significaban? Sin duda, ejemplos como los que presento a continuación contribuirán a un mejor conocimiento de la situación.

Figura 1 a/b: arquero junto con un perro. Una silueta alargada (con una altura de $40 \mathrm{~cm}$ ) y esquemática de un hombre de pie sosteniendo un arco doble, más alto que la figura humana. Los rasgos destacados por el 


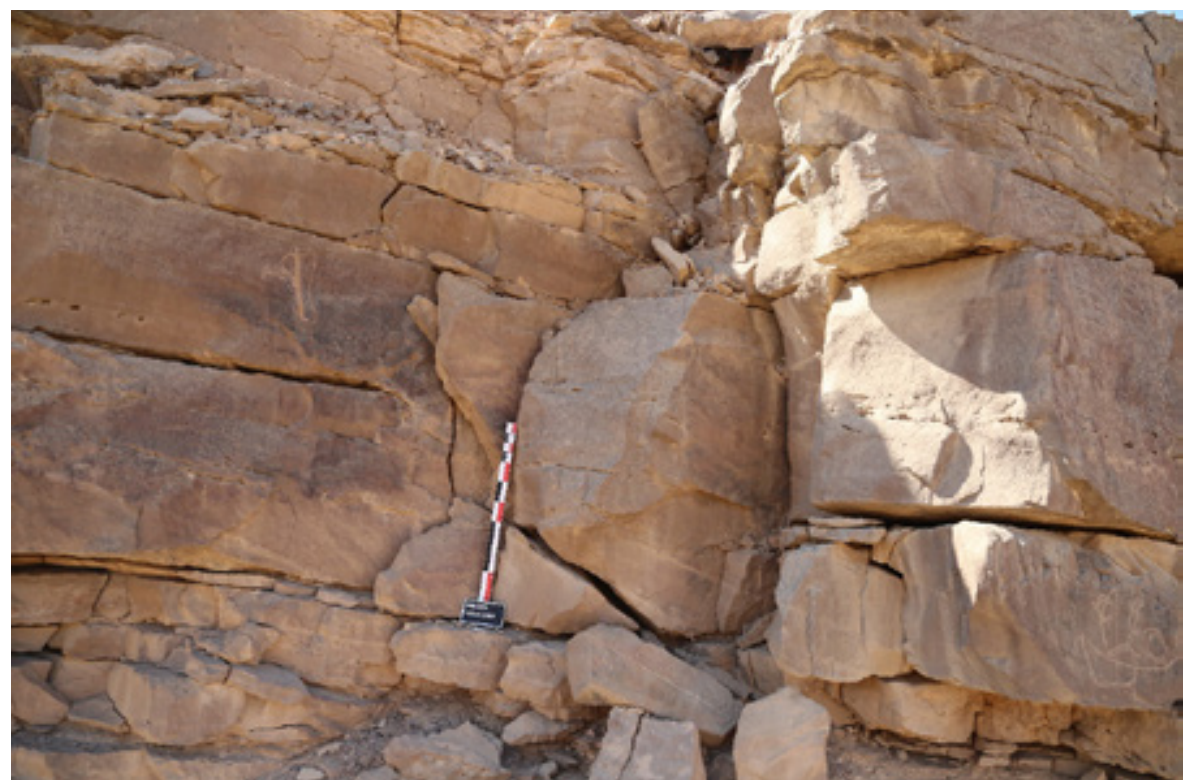

Fig. $1 \mathrm{a}$

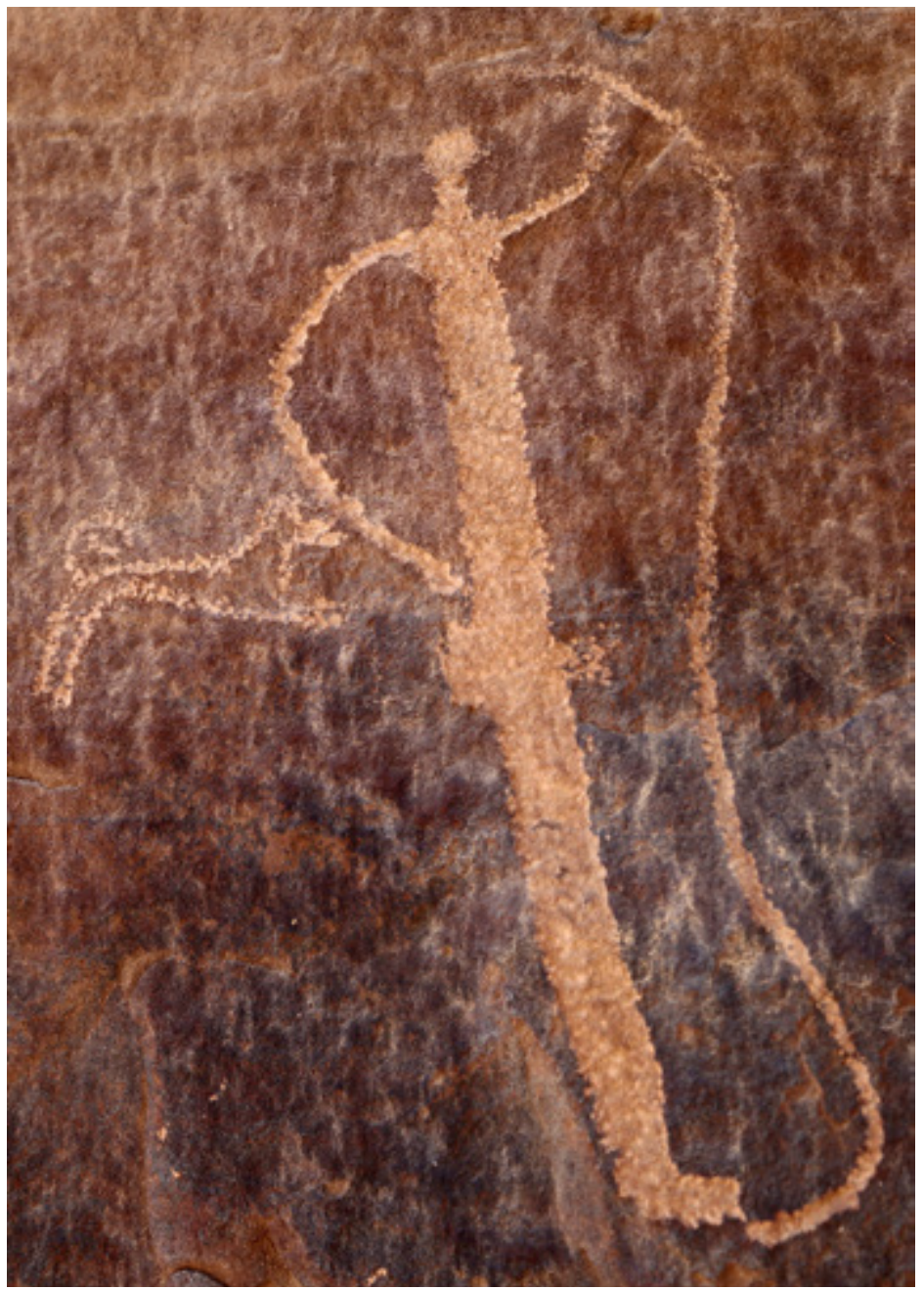

Fig. $1 b$ 


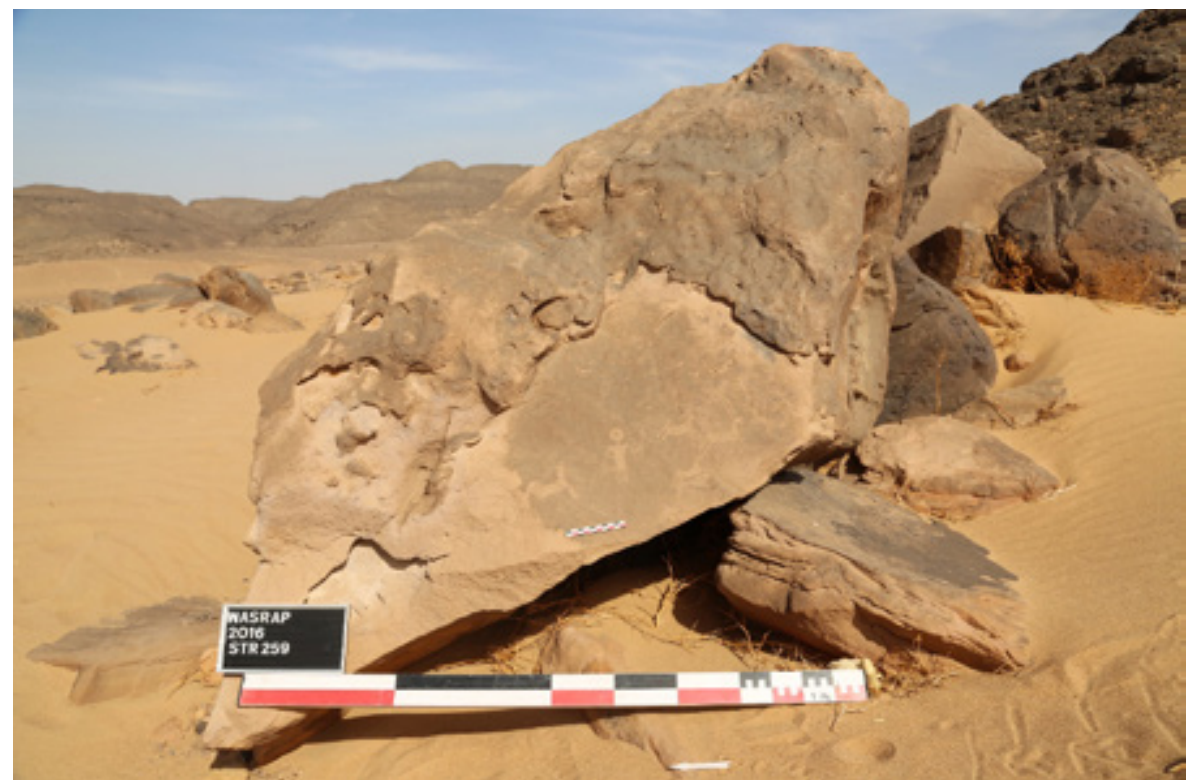

Fig. $2 \mathrm{a}$

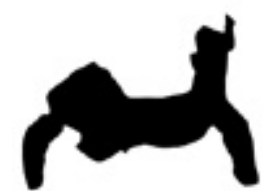

WASRAP 4 2016. L. 259 intopachis: G. Gart

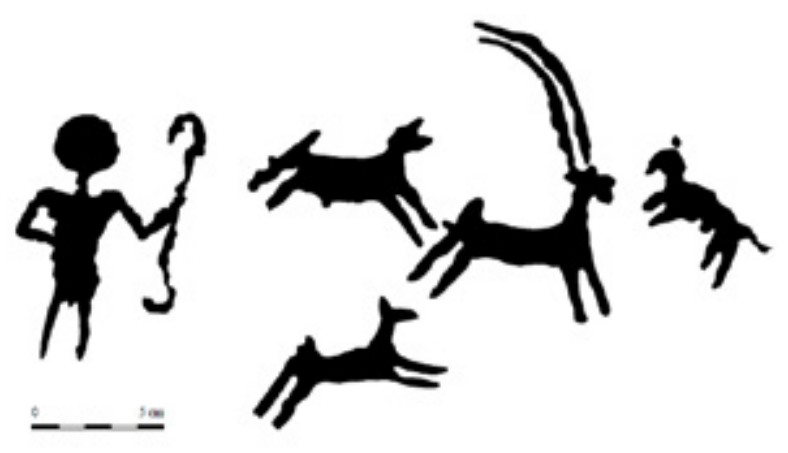

Fig. $2 b$

ejecutor son la cabeza redonda y los glúteos pronunciados, al igual que el falo (probablemente provisto de estuche). Detrás del mismo, un perro cazador aparentemente en movimiento y con la cola enroscada hacia arriba. Los perros son el aliado natural del cazador, e incluso cuando este último no aparezca en la figuración se sobreentiende su presencia a partir de la figura del perro. Fue hallado en la cara sudeste de un bloque de piedra aislado en el Locus $n^{\circ} 082$ de Wadi Abu Subeira.

Figura 2 a/b: cacería con arco y perros de un bóvido salvaje, y animal cuadrúpedo (?) detrás del cazador, cuya seña distintiva además de su corta estatura es el falo. Tres perros rodean a un bóvido, que por sus cuernos largos y curvados hacia detrás podría ser un órix de cuernos de cimitarra u órix blanco (Oryx dammah), una especie hoy extinta en estado salvaje, o también un íbex (Capra ibex) según la interpretación de los excavadores. El cazador tiene cabeza redonda, recordando a los "round heads" del desierto libio (Zboray, 2012: 219), aunque sólo ese detalle estilístico lo emparenta. Más difícil de identificar es la figura que se encuentra detrás del cazador, que se encuentra en una zona deteriorada de la roca pero podría ser otro 


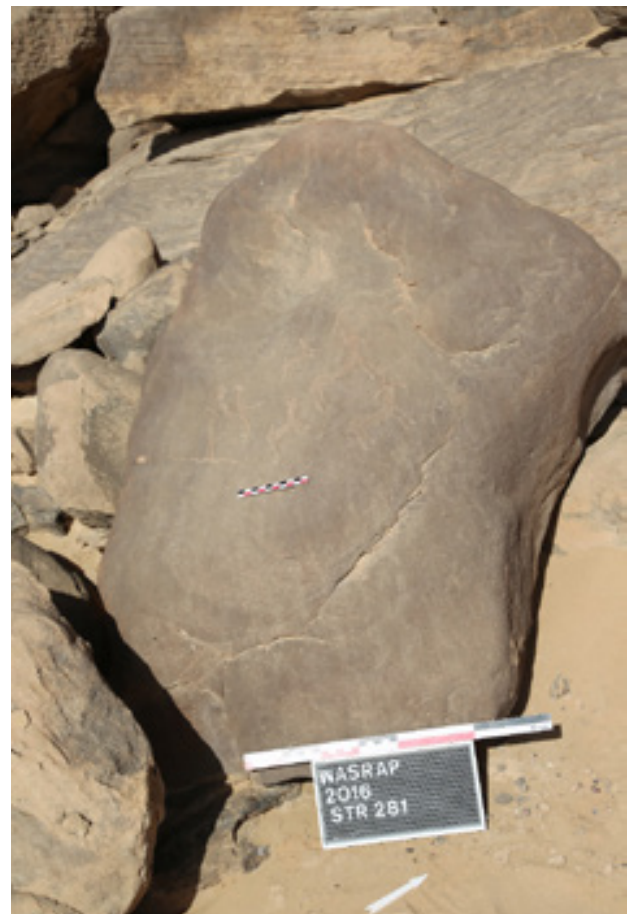

Fig. $3 a$
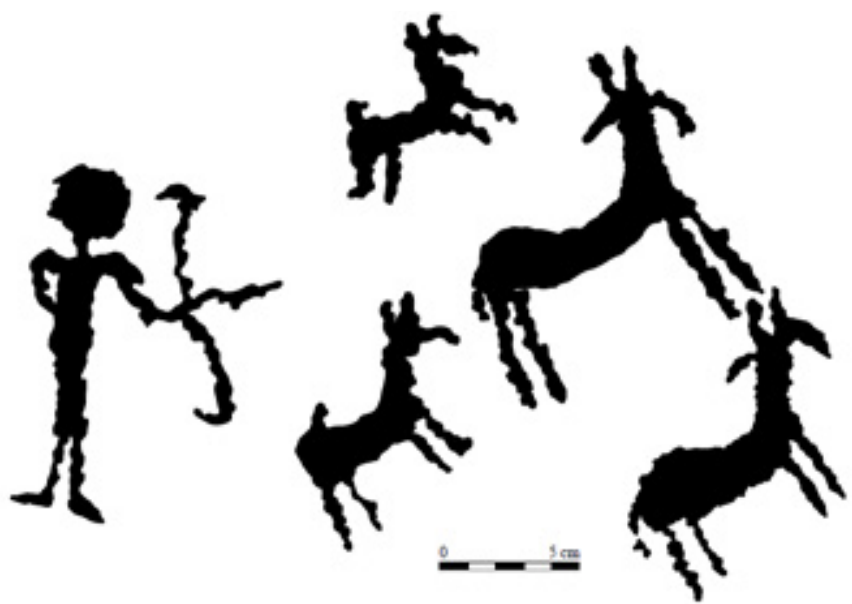

WASRAP 4 2016. L. 281.

Inflographie: G. Gatt

Fig. $3 b$

animal cuadrúpedo, ya un perro o un animal salvaje. La escena tiene un largo de $48 \mathrm{~cm}$ y se encuentra en la cara este de un bloque de piedra aislado en el Locus $n^{\circ} 259$.

Figura 3 a/b: cacería de asnos salvajes con arco, flecha y perros. En este caso, el cazador tiene una flecha colocada en el arco. Dos perros persiguen a dos asnos salvajes, uno de los cuales tiene la cabeza vuelta hacia sus perseguidores. Estos animales tenían la particularidad de ser el único animal del desierto cuya muerte se representaba en la iconografía predinástica (Hendrickx y Eyckerman, 2015: 200), aparentemente para conjurar simbólicamente su gran poder negativo (Huyge, 2009). La figuración no tiene superposiciones y se encuentra en un bloque de piedra aislado, en el Locus $\mathrm{n}^{\circ} 218$ del Wadi, mirando en dirección sudeste y ligeramente inclinado hacia abajo. Todo el panel tiene unas dimensiones de $30 \mathrm{~cm}$ por $20 \mathrm{~cm}$.

Los casos presentados aquí por primera vez pueden considerarse paradigmáticos de la situación de los estudios del arte rupestre egipcio, caracterizada por la atomización en sitios particulares con escaso intercambio entre ellos y por el hecho de que sólo un pequeño número de los sitios descubiertos está publicado. La sola descripción, por más exhaustiva que se pretenda, no alcanza. Hacen falta más estudios generales, que expliquen la divergencia entre cultura material e iconografía y no sólo en una perspectiva local, sino en la generalidad. El esfuerzo de Stan Hendrickx, además de por sus trabajos por el impulso que dio a otros investigadores (entre los cuales me incluyo), es un ejemplo notable. El arte rupestre egipcio está destinado a alumbrar las formas de relación entre diversos grupos humanos y los procesos sociopolíticos más salientes del IV milenio a.C., de los cuales el más importante es sin duda la aparición de un Estado en el Valle del Nilo. 


\section{Q Bibliografía}

»Hendrickx, S. y Gatto, M. C. (2009). A Rediscovered Late Predynastic - Early Dynastic Royal Scene from Gharb Aswan (Upper Egypt), en: Sahara 20: 147-150.

"Hendrickx, S. y Eyckerman, M. (2015). Les animaux savages dans l'Égypte prédynastique, en: Massiera, M., Mathieu, B. y Rouffet, Fr. (eds.), Apprivoiser le sauvage / Taming the Wild, (Cahiers de l'ENiM, 11). Montpellier: Université Paul Valéry Montpellier 3-CNRS, 197-210.

» Huyge, D. (1998). 'Battered Bulls’: Rock Art Destruction in Egypt, en: African Archaeological Review 15/1: 3-11.

»Huyge, D. (2009). Detecting Magic in Rock Art: The Case of the Ancient Egyptian 'Malignant Ass', en: Riemer, H., Förster, M., Pöllath, N. (eds.), Desert Animals in the Eastern Sahara: Status, Economic Significance and Cultural Reflection in Antiquity. Proceedings of an Interdisciplinary ACACIA Workshop Held at the University of Cologne December 14-15, 2007, (Colloquium Africanum, 4). Colonia: Heinrich-Barth-Institut, 293-307.

» Judd, A. M. (2009). Petroglyphs of the Eastern Desert of Egypt: Content, Comparisons, Dating and Significance. Tesis doctoral. University of Liverpool.

"Lankester, F. D. (2013). Desert Boats. Predynastic and Pharaonic Era Rock-art in Egypt's Central Eastern Desert: Distribution, Dating and Interpretation, (BAR, 2544). Oxford: Archeopress.

»Piquette, K., Graff, G., Kelany, A. y El-Bialy, M. (2017). Documenting a New Hunting Scene from Wadi Abu Subeira with Reflectance Transformation Imaging, en: Midant-Reynes, B., Tristant, Y. y Ryan, E. M. (eds.), Egypt at its Origins 5. Proceedings of the Fifth International Conference "Origin of the State. Predynastic and Early Dynastic Egypt", Cairo, 13th - 18th April 2014. Lovaina: Peeters, 883-903.

» Riemer, H. (2009). Prehistoric Rock Art Research in the Western Desert of Egypt, en: Archéo-Nil 19: 31-46.

» Schweinfurth, G. (1912). Über alte Tierbilder und Felsinschriften bei Assuan, en: Zeitschrift für Ethnologie 44/3-4: 627-658.

»Wengrow, D. (2006). The Archaeology of Early Egypt. Social Transformations in North-East Africa, c. 10.000 to 2.65o BC. Cambridge: Cambridge University Press [trad. al castellano de María José Aubet, La arqueología del Egipto arcaico. Transformaciones sociales en el noreste de África (10.000 - 2.650 a.C.). Barcelona: Bellaterra].

»Zboray, A. (2012). A Revision of the Identified Prehistoric Rock Art Styles of the Central Lybian Desert (Eastern Sahara) and Their Relative Chronology, en: Proceedings of the International Colloquium 'The signs of which times?' Chronological and Palaeoenvironmental Issues in the Rock Art of Northern Africa, Bruxelles, 3-5 June 2010. Bruselas: Royal Academy for Overseas Sciences, 217-255. 